\title{
Sentence and Connected Speech Perception Abilities of Students with Cochlear Implant in Inclusive Classroom
}

\author{
Sangyong Shim ${ }^{1}$, Hyunjoo Lee ${ }^{1}$, Kisung Lee ${ }^{1}$, Yoonsun Lee ${ }^{1}$, Jonghyun Park ${ }^{1}$, Hyunsook Jang ${ }^{2}$ \\ 'Department of Speech Pathology and Audiology, Graduate School, Hallym University, Chuncheon, Korea \\ ${ }^{2}$ Division of Speech Pathology and Audiology, Research Institute of Audiology and Speech Pathology, College of Natural Sciences, Hallym University, \\ Chuncheon, Korea
}

Received: August 27, 2019

Revised: October 8, 2019

Accepted: December 3, 2019

Correspondence:

Hyunsook Jang, PhD

Division of Speech Pathology and

Audiology, Research Institute

of Audiology and Speech Pathology,

College of Natural Sciences,

Hallym University, 1 Hallymdaehak-gil,

Chuncheon 24252, Korea

Tel: +82-33-248-2218

Fax: +82-33-256-3420

E-mail: hsjang@hallym.ac.kr
Purpose: As the number of cochlear implant (CI) students has steadily increased in Korea, the number of $\mathrm{Cl}$ students enrolled in inclusive classrooms has also risen. The present study aimed to investigate speech perception abilities at the sentence and connected speech levels of the $\mathrm{Cl}$ students in inclusive classroom settings and to analyze the effects of chronological age, age at $\mathrm{Cl}$ implantation, and wearing period of $\mathrm{Cl}$ on speech perception. Methods: A total of 63 students were recruited from elementary (30 students) and secondary (33 students) schools. The speech perception were assessed by three sub-tests from the Korea National Institute for Special Education-Developmental Assessment of Speech Perception: Sentence Recognition Test (SRT), Sentence Comprehension Test (SCT), and Connected Speech Test (CST). Results: The results showed that there was no significant difference between SRT and SCT, but performances in CST were significantly poorer than those in sentence-level tests for both $\mathrm{Cl}$ student groups. Also, both elementary and secondary school $\mathrm{Cl}$ students showed, individually, a wide range of differences in performance across all tests. In SRT, SCT, and CST, $30-53 \%$ of the elementary and $23-39 \%$ of the secondary $\mathrm{Cl}$ students did not reach the norm (-2 standard deviation) ranges, when compared to their normal peers. Multiple regression analysis indicated that the effects of three variables on speech perception were not significant. Conclusion: The findings of this study suggest that the $\mathrm{Cl}$ students in the inclusive classroom need individualized rehabilitative and educational supports.

Key Words: Inclusive classroom, Cochlear implant, Korea National Institute for Special EducationDevelopmental Assessment of Speech Perception, Sentence test, Connected Speech Test.

\section{INTRODUCTION}

말지각은 말소리의 음향학적 정보를 처리하는 능력으로 음 소, 단어, 문장, 이야기 등의 말소리 정보를 탐지, 변별, 확인, 이 해하는 것을 말한다(Erber, 1982; Locke, 1980). 인공와우 착 용 아동의 말지각은 건청 아동과 마찬가지로 위계적으로 발달 하지만 개개인마다 말지각 발달 수준이 다양하게 나타날 수 있 다(Davidson et al., 2011; Geers et al., 2008; Manrique et al., 2004; Niparko et al., 2010). 인공와우 착용 아동의 말지각 발 달에 영향을 주는 변인은 다양하나 대다수의 연구에서 인공와 우 수술 시기가 빠를수록 인공와우 사용자들의 말지각 수행력 이 향상되는 것으로 보고하였으며(De Raeve, 2010; Manrique

(c) This is an Open Access article distributed under the terms of the Creative Commons Attribution Non-Commercial License (https://creativecommons.org/licenses/by-nc/4.0) which permits unrestricted non-commercial use, distribution, and reproduction in any medium, provided the original work is properly cited. et al., 2004; Svirsky et al., 2004), 인공와우 수술 후 착용 기간 에 따른 듣기 경험이 많을수록 그에 비례하여 말지각 능력이 향상된다고 하였다(Beadle et al., 2005; Uziel et al., 2007; Waltzman et al., 2002). 인공와우 수술 후 5년 동안 개방형 (open-set) 단어 및 문장 인지 수행력이 점진적으로 증가하며 (Waltzman et al., 2002), 더 나아가 다수의 연구들이 인공와우 수술 5 년 후 혹은 10 년 이상 경과한 후에도 유의한 말지각 향 상을 보인다고 하였다(Beadle et al., 2005; Davidson et al., 2011; Uziel et al., 2007). 그러나 몇몇 연구들은 인공와우 착용 학생이 학령기나 청소년기 연령에 도달할 경우 개인차로 인해 조기 인공와우 수술과 듣기 경험이 더 이상 말지각 능력에 영 향을 미치지 않는다고 하였다(Dunn et al., 2014; Geers, 2004; Geers et al., 2008).

조기 인공와우 착용으로 말지각 능력이 최대 정상 아동의 능 력만큼 도달할 수 있다는 긍정적인 결과들(De Raeve, 2010; 
Manrique et al., 2004; Svirsky et al., 2004)로 인해 전 세계적 으로 인공와우 착용 아동의 비중이 지속적으로 증가하고 있다. 국내의 경우도 특수교육 대상 청각장애 학생 중 인공와우를 착 용한 학생이 2011년 49.9\%에서 2017년 54.9\%로 증가하는 추세 를 보이고 있다(Korea National Institute for Special Education, 2011, 2017). 최근 특수교육통계(Ministry of Education, 2018)에 따르면 특수교육 대상 청각장애 학생 3,268 명 중 1,801 명(55.11\%)이 전일제 일반학급에, 687명(21.02\%)이 특수학급 에, 나머지 780명(23.87\%)이 특수학교에 재학 중으로 나타났으 며, 이 중 통합교육 환경에 배치된 전체 학생 2,488명(76.13\%) 중 $56.2 \%$, 특수학교에 배치된 학생 중 $50 \%$ 가 인공와우를 착용 하고 있는 것으로 나타났다. 인공와우 학생의 통합교육은 교육 비용의 절감, 의사소통 기술과 사회 적응력의 향상 등 긍정적인 결과들로 국내뿐만 아니라 국외에서도 지속적으로 지지하며 (Huber et al., 2008; Nicholas \& Geers, 2003; Venail et al., 2010), 학년에 상관없이 인공와우 착용 학생의 통합교육 배치에 대한 선택이 우선시되고 있는 추세이다(Venail et al., 2010).

통합학급은 인공와우 착용 학생에게 풍부한 음향학적 자극 으로 말지각 발달을 촉진하는 환경을 제공하기도 하지만 말지 각 능력이 충분히 발달하지 못한 학생에게는 적응하기 어려운 환경이 될 수 있다. 통합학급에서 인공와우 착용 학생이 또래 수준의 학습 발달을 성취하기 위해서는 교사의 복잡한 지시나 설명을 듣고 이해해야 하고 교실 소음 환경에서 교사나 다른 학생들과 대화하고 이해할 수 있어야 한다. 이때 말소리 듣기에 제한이 있는 학생은 수업에 적극적으로 참여하지 못해 결국 어 휘력 및 학습 수준의 저하까지 초래하는 결과를 보이기도 하며 (Convertino et al., 2014; Fagan \& Pisoni, 2010; Heo \& Kim, 2010; Park et al., 2016) 듣기를 통한 사회적 활동이 더욱 강조되 는 초등학교와 중·고등학교 시기에 사회 관계를 맺는 일에도 어 려움을 보일 수 있다(Davidson et al., 2011). 이러한 이유들로 통합학급에 재학 중인 청각장애 학생 중 일부는 학습, 학교 적 응, 또래 관계 등에서 어려움을 호소하거나 만족도가 낮은 것으 로 나타났으며(Huh, 2017; Jeon \& Jeong, 2015; Park \& Shin, 2018) 더 나아가 이러한 어려움이 축적되면서 통합학급에 재학 했던 초등학교 고학년이나 중·고등학교 청각장애 학생 중 $30 \%$ 정도가 특수학교로 전학한다고 보고하였다(Huh, 2017).

$\mathrm{Heo} \& \operatorname{Kim}(2010)$ 은 5세 이하에 인공와우 수술을 받고 통 합 환경에 있는 초등학생을 대상으로 Categories of Auditory Performance (Archbold et al., 1995)를 사용하여 일상생활 기 능적 청각적 수행력을 측정하였으며, 청각적 수행력이 언어능 력, 사회-정서 적응력, 학업 성취, 통합 적응력과 상관성이 있 음을 보고하였다. 이러한 결과로 인공와우 착용 학생의 일반학 교에서의 적응 및 통합의 성과를 최대화하기 위해 학생의 특성
에 적절한 교육적 배려와 지원이 이루어져야 하며, 이에 대한 선행적 절차로 실제 교육 환경에서 보이는 아동의 수행력이 평 가되어야 함을 강조하였다.

말지각 수행력 평가의 측면에서 통합교육 내 인공와우 착용 학생들이 교육 받기에 적절한 말지각 능력을 가지고 있는지, 정 상청력 학생들의 수행력과 비교했을 때 어느 정도 차이가 있는 지 어떠한 변인들이 말지각 수행력과 관련이 있는지에 대해 살 펴볼 필요가 있으나 국내 학령기 이상 인공와우 착용 학생을 대상으로 진행된 말지각 연구들은 주로 단어 수준(Kim et al., 2008; Kim et al., 2014; Lee \& Sim, 2015)에서 이루어졌으며, 문장이나 이야기 수준에서 말지각 능력을 살펴본 연구는 제한 적이다. Park et al.(2016)은 문장 및 이야기 수준의 말지각 능 력이 학령기 및 청소년기 인공와우 착용 학생의 학업 수행은 물 론 사회적 관계에까지 영향을 미칠 수 있어 이에 대한 체계적인 평가가 요구된다고 하였고, 더 나아가 Song et al.(2010)은 문장 및 이야기를 듣고 확인(identification)하거나 이해(comprehension)하는 능력은 의사소통과 학습 환경에서의 실제적인 말지 각 능력을 반영하므로 교육 및 재활 계획 수립과 교육적 지원에 중요한 근거를 제공할 수 있다고 하였다. 이러한 필요성에 의해 본 연구의 목적은 국내 일반학교 통합학급에 재학 중인 인공와 우 착용 초등학생과 중·고등학생의 문장 인지, 문장 이해, 이야 기 이해 수준에서의 말지각 능력을 확인하였으며, 또한 생활연 령, 수술 시기, 착용 기간이 학령기 이후 말지각 능력에 미치는 영향의 정도를 알아보는 데 있다.

\section{MATERIALS AND METHODS}

\section{연구 대상}

본 연구는 서울, 대구, 강원 지역의 통합학급에 재학 중인 인 공와우를 착용한 초등학생 30 명(평균 연령 $123.77 \pm 21.82$ 개 월), 중·고등학생 33명(평균 연령 $188.30 \pm 19.72$ 개월) 총 63명 (남: 33명, 여: 30명)을 대상으로 하였다. 연구에 참여한 모든 대상자들은 첫째, 선천성 및 언어 습득 이전에 난청이 있고, 둘 째, 양측 귀 모두 고도 이상의 난청으로 편측 또는 양측에 인공 와우를 착용했으며, 셋째, 청각장애 이외 다른 중복장애가 없 고, 넷째, 주 의사소통 방식으로 구화를 사용하였다. 첫 번째 인 공와우 수술 시기 기준으로 수술 연령은 초등학생이 14 52개월 (평균 $27.67 \pm 11.11$ )이었으며, 중·고등학생이 15 83개월(평균 $39.82 \pm 19.44$ )이었다. 말지각 및 언어 습득에 결정적 시기인 2 세 전후를 기준으로(De Raeve, 2010; Manrique et al., 2004; Svirsky et al., 2004) 구분하였을 때 초등학생 30명 중 16 명이 24개월 이전에, 나머지 14명은 24개월 이후 수술을 받았으며, 중·고등학생의 경우는 전체 33 명 중 10 명이 24 개월 이전에, 23 명 
Table 1. Demographic information of participants

\begin{tabular}{lcccccc}
\hline Group & $\mathrm{n}(\mathrm{M} / \mathrm{F})$ & Chronological age (mon) & Ages at CI (mon) & Wearing period of CI (mon) & dB of CI (dB) & Ears of CI \\
\hline Elementary & $30(16 / 14)$ & $123.77( \pm 21.82)$ & $27.67( \pm 11.11)$ & $95.20( \pm 24.72)$ & $29.00( \pm 6.56)$ & Bi: 9, Uni: 21 \\
Secondary & $33(17 / 16)$ & $188.30( \pm 19.72)$ & $39.82( \pm 19.44)$ & $151.24( \pm 20.92)$ & $28.54( \pm 6.25)$ & Bi: 15, Uni: 18 \\
\hline
\end{tabular}

Values are presented as mean and standard deviation. M: male, F: female, CI: cochlear implant, mon: month, dB: decibel, Bi: bilateral, Uni: unilateral

이 24개월 이후에 수술을 받았다. 대상자의 인공와우 착용 기 간은 초등학생이 38 134개월(평균 $95.20 \pm 24.72)$, 중·고등학 생이 104 194개월(평균 $151.24 \pm 20.92)$ 이었다. 각 집단별 연 구 대상자의 성별, 생활 연령, 인공와우 수술 시기, 인공와우 착 용 기간, 편측 또는 양측 인공와우 착용 역치 $(500,1,000,2,000$ $\mathrm{Hz}$ 주파수의 삼분법 기준), 인공와우 착용 귀에 대한 정보는 Table 1과 같다.

\section{검사 도구}

연구 대상자의 문장 및 이야기 수준 말지각 능력을 확인하기 위하여 국립특수교육원 말지각발달검사(Korea National Institute for Special Education-Developmental Assessment of Speech Perception, KNISE-DASP)의 하위 검사인 문장인지 검사(Sentence Recognition Test, SRT), 문장이해검사(Sentence Comprehension Test, SCT), 이야기이해검사(Connected Speech Test, CST)를 사용하였다(Song et al., 2010). KNISE$\mathrm{DASP}$ 은 국내 청각장애 학생의 교육적 계획 및 지원을 위해 개 발되어 표준화가 이루어졌으며 음소, 단어, 문장 및 이야기 등 다양한 말소리 자극 단위에 대한 탐지, 변별, 확인, 이해 등을 평가할 수 있도록 구성되어 있다. 이를 통하여 청각장애 학생의 개인별 말지각 발달 수준에 대한 정보뿐 아니라 더 나아가 정 상청력 아동의 규준과 비교할 수 있다.

SRT는 학교 생활 관련 10개 문장(40 목표 단어)으로 구성되 어 있으며, 검사자가 말하는 문장을 대상자가 듣고 따라 말하 는 검사로 정반응한 목표 단어를 백분율로 점수화하였다. SCT 는 10 개의 문장을 대상자가 듣고 이해한 뒤 답하는 검사로 정 반응한 문장을 백분율로 점수화하였다. CST는 2개에서 6개 문 장의 이야기로 구성되어 있으며, 대상자가 이야기를 듣고 내용 을 이해하여 관련 질문에 적절히 대답하는 검사로 정반응한 답 변에 대해 백분율로 점수화하였다. 모든 검사는 청각적 단서만 을 사용하는 auditory-only (AO) 상황에서 보기가 제시되지 않는 개방형(open-set)으로 진행하였다.

\section{연구 절차}

본 연구는 자발적으로 참여를 희망하고 부모의 동의를 얻은 일반학교에 재학 중인 인공와우 착용 학생들을 대상으로 실시 하였다. 먼저 보장구 점검을 통해 보장구 상태를 확인한 후 인
공와우 착용 학생의 보장구 역치 평가를 실시하였다. 보장구 역 치 평가는 청력 검사기(GSI 61, Grason-stadler, Eden Prairie, $\mathrm{MN}, \mathrm{USA}$ )를 사용하여 방음실에서 실시하였으며, 인공와우를 착용한 상태에서 스피커를 0 도에 위치시키고 $1 \mathrm{~m}$ 거리를 유지 하여 진행하였다. 말지각 검사는 조용한 방에서 검사자가 학생 의 $1 \mathrm{~m}$ 정도의 정면에서 $\mathrm{AO}$ 상황으로 일상생활 대화 수준으 로 자극을 제시하여 실시하였으며, SRT, SCT, CST 순으로 진 행하였다. 각 검사 간 또는 요구에 따라 휴식 시간을 제공하였 으며, 검사 소요 시간은 평균 30 분 정도였다.

\section{자료 분석}

수집한 자료는 SPSS 21.0(IBM Corp., Armonk, NY, USA) 을 이용하여 통계적 분석을 실시하였다. 인공와우 학생의 자료 를 초등학교 집단과 중·고등학교 집단으로 문장 수준 검사 (SRT, SCT)와 이야기 수준 검사(CST)의 평균과 표준편차를 구하였으며, 각 집단별 SRT, SCT, CST 점수에 차이가 있는지 비교하기 위해 반복측정 일원분산 분석과 사후 분석으로 대비 검정을 실시하였다. 또한 각 집단별 수술 시기, 착용 기간, 생활 연령이 SRT, SCT, CST 점수에 미치는 영향을 알아보기 위하 여 다중회귀분석을 실시하였다,

인공와우 학생의 개인별 점수를 KNISE-DASP의 정상 규준 과 비교하였다. KNISE-DASP 표준화 연구(Song et al., 2010) 에서 SRT와 SCT 점수는 건청 초등학생 1학년 수준에서 각각 $98.1 \pm 3.55 \%$ 와 $96.00 \pm 7.90 \%$ 로 나타났으며, 그 이상 연령 평균 점수와도 유의한 차이가 없었다. 따라서 본 연구에서는 평 가에 참여한 모든 인공와우 학생의 SRT와 SCT 정반응률을 동 일한 규준으로 비교할 수 있는 건청 초등학생 1학년 -2 표준편 차(standard deviation, SD) (SRT는 91\%, SCT는 80.2\%)와 비교 하였다. 이야기 수준의 말지각 검사인 CST의 규준은 초등학생 1 학년부터 6학년까지만 적용 가능하였다. 따라서 초등학생 집 단의 CST 점수는 KNISE-DASP 해당 학년 규준에 적용하여 건청아동 또래와의 차이를 확인하였으며, 중·고등학생 집단은 KNISE-DASP 규준에 해당 연령이 포함되어 있지 않기 때문 에 건청 초등학생 6학년 규준과 비교하여 이야기 말지각 수준 을 알아보았다. 


\section{RESULTS}

\section{초등학생의 말지각 능력}

본 연구의 인공와우를 착용한 초등학생의 문장 및 이야기 이 해 수준에 대한 말지각 수행력 결과(Table 2), 평균과 표준편차 는 SRT 81.90( \pm 22.95$) \%$, SCT 83.50( \pm 27.58$) \%$, CST 61.43( \pm 35.72)\%였다. 검사 간 평균 차이를 비교한 결과 유의한 차이를 보 였으며 $[\mathrm{F}(1.491,43.243)=21.543, p=0.001]$, 사후 검정으로 대비 검정을 실시한 결과 문장 수준의 검사인 SRT와 SCT 간에는 유 의한 차이가 없었으나 $(p>0.05)$, 이야기이해검사인 CST는 각 문
장 검사에 비해 유의미하게 낮은 점수 차이를 보였다 $(p>0.05)$.

본 연구에 참여한 인공와우 착용 초등학생의 개인별 문장 수준의 말지각 능력을 확인하기 위해 SRT와 SCT 점수를

Table 2. Results of SRT, SCT, and CST on elementary school students

\begin{tabular}{ccccc}
\hline Test & Mean $( \pm$ SD $)$ & F & $p$-value & Post -hoc \\
\hline SRT & $81.90( \pm 22.95)$ & & & \\
SCT & $83.50( \pm 27.58)$ & 21.543 & $<0.001^{*}$ & SRT and SCT $>$ CST \\
CST & $61.43( \pm 35.72)$ & & & \\
\hline
\end{tabular}

Values are presented as means and SDs. Unit: $\% .{ }^{*} p<0.001$. SRT: Sentence Recognition Test, SCT: Sentence Comprehension Test, CST: Connected Speech Test, SD: standard deviation
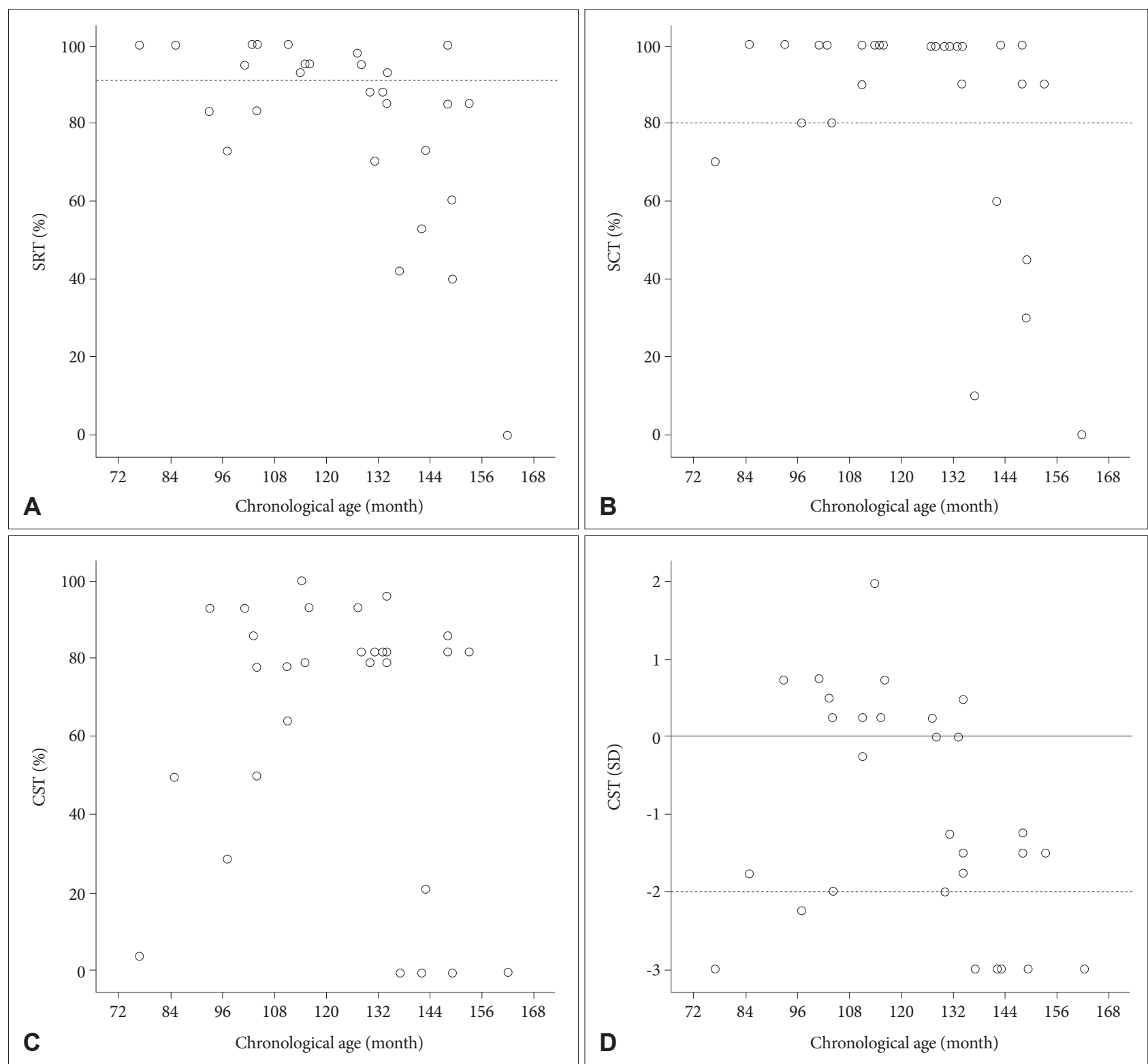

Figure 1. Results of sentence and connected speech tests for elementary students with Cl. A: SRT scores. B: SCT scores. C: CST scores. D: comparing CST scores with the norm of KNISE-DASP. Dashed lines are -2 SD of the norms of KNISE-DASP. SRT: Sentence Recognition Test, SCT: Sentence Comprehension Test, CST: Connected Speech Test, Cl: cochlear implant, SD: standard deviation, KNISE-DASP: Korea National Institute for Special Education-Developmental Assessment of Speech Perception. 
KNISE-DASP의 건청 초등학생 1학년 규준과 비교하였다 (Figure 1A, B). SRT의 경우 초등학생 16명(53.33\%)이 $-2 \mathrm{SD}$ 에 해당하는 점수인 $91 \%$ 미만을 나타냈으며, SCT의 경우 초등 학생 9명(30.00\%)이 $-2 \mathrm{SD}$ 점수인 $80.2 \%$ 보다 낮은 정반응률 을 나타내었다. 반면 SRT에서 초등학생 7명(23.33\%), SCT에서 초등학생 16명(53.33\%)이 $100 \%$ 정반응률을 나타내었다. CST 평 균 점수는 $61.43( \pm 35.72) \%$ 였으며, CST 결과를 KNISE-DASP 의 각 학년별 규준과 비교한 결과(Figure 1C, D), 9명(30.00\%)은 KNISE-DASP의 해당 학년 $-2 \mathrm{SD}$ 보다 낮은 정반응률을 나타 냈으나 11명(36.67\%)은 각 학년 규준 평균 점수보다 높은 점수 를 나타내었다.

생활 연령, 수술 시기, 착용 기간이 초등학생 집단 문장 및 이야기 수준 말지각 검사 점수에 미치는 영향을 확인하기 위해 다중회귀 분석을 실시한 결과(Table 3), 생활 연령과 수술 시기 는 말지각 점수에 영향을 미치지 않는 것으로 나타났으나 $(p>$ $0.05)$, 착용 기간이 길어질수록 $[\mathrm{SRT}(\beta=-0.603, t=-3.928, p<$ $0.01), \operatorname{SCT}(\beta=-0.469, t=-2.757, p<0.05)$, CST $(\beta=-0.397$, $t=-2.246, p<0.05)]$ 말지각 점수가 유의하게 낮아지는 것으 로 나타났으며, 착용 기간이 말지각 점수를 설명하는 설명력의 정도는 SRT, SCT, CST 각각 $36.4 \%, 22.0 \%, 15.7 \%$ 였다.

\section{중·고등학생의 말지각 능력}

인공와우를 착용한 중·고등학생의 문장 수준과 이야기 수준

Table 3. Results of multiple regression-elementary school students

\begin{tabular}{llccc}
\hline Test & \multicolumn{1}{c}{ Relative factor } & $\mathrm{R}^{2}$ & $\beta$ & $t$ \\
\hline SRT & Chronological age & & -0.152 & -0.477 \\
& Age at CI & 0.364 & -0.083 & -0.478 \\
& Wearing period of CI & & -0.603 & $-3.928^{\dagger}$ \\
SCT & Chronological age & & -0.247 & -0.706 \\
& Age at CI & 0.220 & -0.135 & -0.704 \\
& Wearing period of CI & & -0.469 & $-2.757^{*}$ \\
CST & Chronological age & & -0.080 & -0.217 \\
& Age at CI & 0.157 & -0.040 & -0.198 \\
& Wearing period of CI & & -0.397 & $-2.246^{*}$ \\
\hline
\end{tabular}

${ }^{*} p<0.05,{ }^{\dagger} p<0.01$. SRT: Sentence Recognition Test, SCT: Sentence Comprehension Test, CST: Connected Speech Test, SD: standard deviation, CI: cochlear implant

Table 4. Results of SRT, SCT, and CST on secondary school students

\begin{tabular}{ccccc}
\hline Test & Mean $( \pm$ SD $)$ & F & $p$-value & Post-hoc \\
\hline SRT & $86.82( \pm 19.20)$ & & & \\
SCT & $91.21( \pm 15.16)$ & 19.402 & $<0.001^{*}$ & SRT and SCT $>$ CST \\
CST & $73.00( \pm 26.75)$ & & & \\
\hline
\end{tabular}

Values are presented as means and SDs. Unit: $\% .{ }^{*} p<0.001$. SRT: Sentence Recognition Test, SCT: Sentence Comprehension Test, CST: Connected Speech Test, SD: standard deviation
검사 결과(Table 4), 평균과 표준편차는 SRT 86.82( \pm 19.20$) \%$, SCT 91.21( \pm 15.16$) \%$, CST 73.00( \pm 26.75$) \%$ 였다. 검사 간 평균 차이가 유의하였으며 $[\mathrm{F}(1.424,45.575)=19.402, p<0.001]$, 사후 분석 결과 문장 검사 간 유의한 차이가 없었으나 $(p>0.05)$, 이 야기이해검사는 각 문장 검사에 비해 유의미하게 낮은 점수를 보였다 $(p<0.05)$.

중·고등학생의 개인별 문장 수준의 말지각 능력을 건청 초 등학생 1학년 규준과 비교한 결과, SRT 13명(39.39\%), SCT 5명 (15.15\%)이 -2 SD보다 낮은 정반응률을 나타낸 반면 SRT 15명 (45.45\%), SCT 19명(57.58\%)이 100\% 정반응률을 나타내었다 (Figure 2A, B). 중·고등학생의 개인별 CST 점수는 KNISE$\mathrm{DASP}$ 의 가장 높은 연령 규준인 건청 초등학생 6학년 규준을 사용하여 비교하였으며(Figure 2C, D), 그 결과 13명(39.39\%)이 KNISE-DASP 6학년 규준 $-2 \mathrm{SD}$ 점수인 79.83\%보다 낮았고, 4명(12.12\%)만이 6학년 규준 평균인 94.25\%보다 높은 정반응 률을 나타내었다.

생활 연령, 수술 시기, 착용 기간이 중·고등학생 집단 문장 및 이야기 수준 말지각 검사 점수에 미치는 영향을 확인하기 위해 다중회귀 분석을 실시한 결과(Table 5), 착용 기간 $(\beta=-0.754, t$ $=-2.322, p<0.05)$ 이 SRT와 CST 점수에 유의한 영향을 미치 는 것을 제외하고는 생활 연령, 수술 시기, 착용 기간이 말지각 점수에 영향을 미치지 않는 것으로 나타났으며 $(p>0.05)$, 착 용 기간이 SRT와 CST를 설명하는 설명력의 정도는 각각 $4.2 \%$ 와 $16.4 \%$ 였다.

\section{DISCUSSIONS}

본 연구는 일반학교에 통합된 인공와우 착용 초등학생과 중 고등학생들의 문장 및 이야기 수준의 말지각 능력을 확인하기 위하여 각 학교급별 검사 간 비교와 각 개인별 수행력을 건청 학생의 규준과 비교하였다. 또한 생활 연령, 수술 시기, 착용 기 간이 말지각 점수에 미치는 영향을 살펴보았다. 본 연구에서 사 용한 KNISE-DASP 검사 도구는 음소에서 이야기까지 다양한 어음 자극 수준에서 말지각 능력을 평가하도록 개발되어 12세 이하의 건청 초등학생을 대상으로 표준화가 이루어진 검사이 다. 그러나 Song et al.(2010)은 말지각 특성상 초등학교 6학년 에서 거의 만점에 가까운 평균 점수를 보인다는 것은 그 이상 의 학년에서도 도달할 수 있는 능력으로 기준이 될 수 있음을 의미하므로 초등학생 이상에게도 사용 가능함을 제안하였다. 그러므로 본 연구에서는 각 개인별 수행력을 건청 학생의 규준 과 비교할 때, 중·고등학생의 경우 문장과 이야기 이해 수준에 서 모두 최고점의 학년을 기준으로 비교 분석하였다.

$\mathrm{AO}$ 상황으로 제시되는 open-set 문장을 따라 말하거나 이 

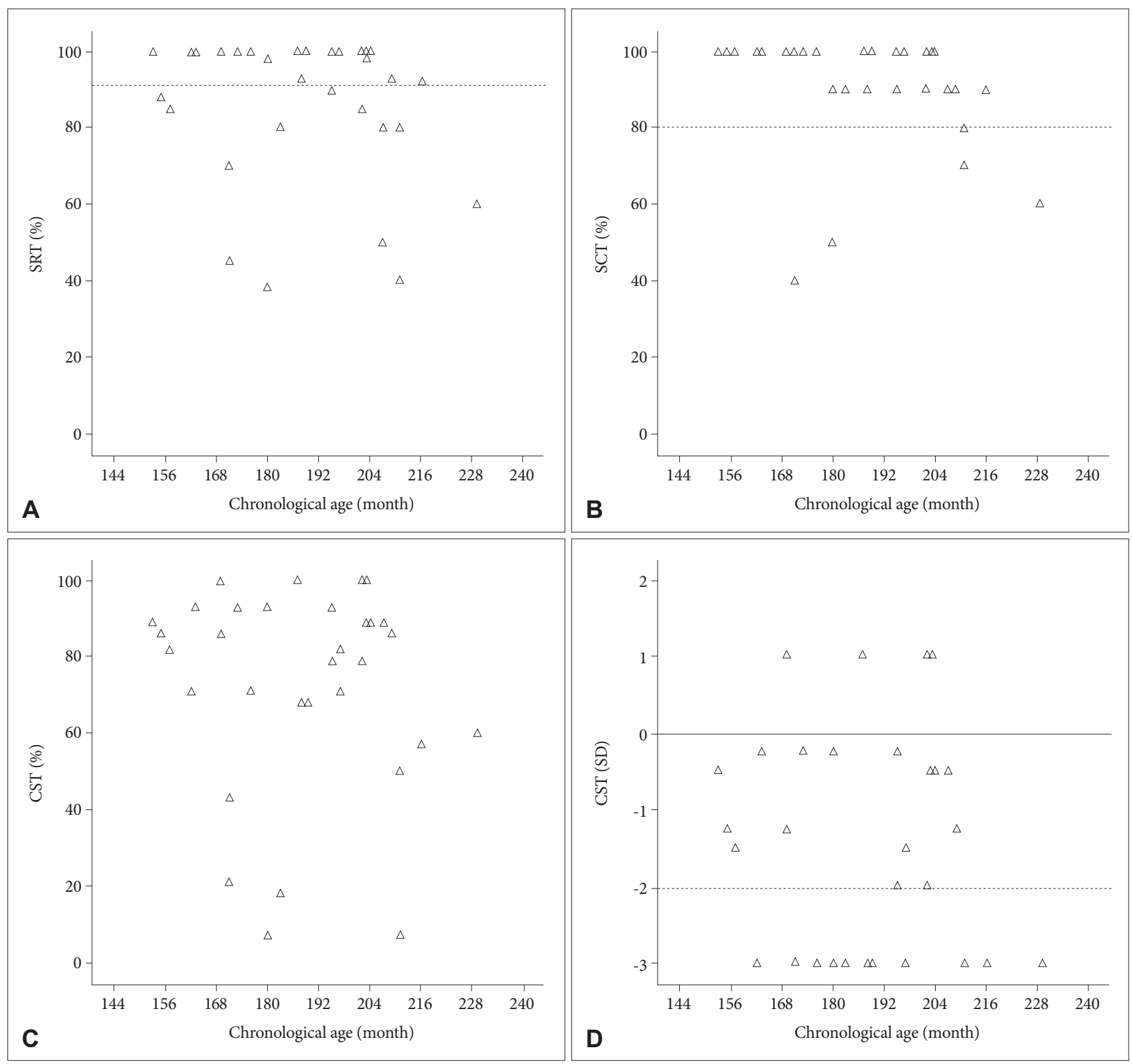

Figure 2. Results of sentence and connected speech tests for secondary students with CI. A: SRT scores. B: SCT scores. C: CST scores. D: comparing CST scores with the norm of KNISE-DASP. Dashed lines are -2 SD of the norms of KNISE-DASP (6th grade). SRT: Sentence Recognition Test, SCT: Sentence Comprehension Test, CST: Connected Speech Test, CI: cochlear implant, SD: standard deviation, KNISEDASP: Korea National Institute for Special Education-Developmental Assessment of Speech Perception.

해하는 능력과 이야기를 이해하는 능력을 살펴보았을 때, 간단 한 문장의 인지나 이해 수준은 초등학생의 경우도 평균 $81 \%$ 이상의 수행력을 보이는 반면 두 집단 모두 이야기 이해 수준 은 문장 수준에 비해 유의미하게 낮은 수행력을 보였다. 이는 말지각 단계 중 이야기 이해가 언어 지식과 언어적 처리 과정을 동반하므로(Tye-Murray, 2015) 인공와우 착용 학생들 중 언어 를 분석하고 이해하는 능력이 부족한 학생의 경우 이야기 이해 수준의 말지각에서 겪을 수 있는 어려움을 반영하고 또한 수행 력에서의 큰 개인차에 기인하는 결과로 해석할 수 있다.
인공와우 착용 초등학생 집단과 중·고등학생 집단 모두 개인 별 문장 및 이야기 수준 말지각 능력은 0 100\%로 큰 개인차를 보였다. 문장 및 이야기 이해 수준에서 초등학생 집단의 30 $53 \%$, 중 ·고등학생 집단의 23 39\%가 건청 규준의 $-2 \mathrm{SD}$ 이하 의 수행력을 보이므로 의사소통과 학습 환경에서 간단한 문장 이나 긴 대화, 듣기 위주의 수업 내용 등을 구체적으로 이해하 는 일에 어려움을 겪을 가능성이 높은 것으로 나타났다. 더하 여 소음 속 교실 환경을 고려할 때 더 많은 비율의 학생들이 말 지각의 어려움을 경험할 것으로 예상된다. 또한 모든 검사에서 
Table 5. Results of multiple regression-secondary school students

\begin{tabular}{llccc}
\hline Test & \multicolumn{1}{c}{ Relative factor } & $\mathrm{R}^{2}$ & $\beta$ & $t$ \\
\hline SRT & Chronological age & & -0.165 & -0.430 \\
& Age at CI & 0.042 & -0.161 & -0.161 \\
& Wearing period of CI & & -0.048 & -0.048 \\
SCT & Chronological age & & -0.053 & -0.141 \\
& Age at CI & 0.067 & -0.205 & -0.605 \\
& Wearing period of CI & & -0.145 & -0.422 \\
CST & Chronological age & & 0.645 & 1.801 \\
& Age at CI & 0.164 & -0.642 & -2.000 \\
& Wearing period of CI & & -0.754 & $-2.322^{*}$ \\
\hline
\end{tabular}

${ }^{*} p<0.05$. SRT: Sentence Recognition Test, SCT: Sentence Comprehension Test, CST: Connected Speech Test, CI: cochlear implant

$0 \%$ 의 수행력을 보인 경우는 27 개월에 수술을 받은 초등학교 5 학년생 1 명으로, 와우 기형과 2차례의 재수술을 보고한 학생 이었다. 이 학생을 제외하면 문장 수준에서 $0 \%$ 를 보인 학생은 없었으나, 이야기 이해 수준에서는 초등학생 집단 중 4명이 $0 \%$ 를 나타내었다. 이러한 말지각 발달 수준을 보이는 학생들의 경 우, 듣기만으로는 수업이나 일상생활 의사소통에 상당한 제약 이 있을 것으로 보여 청각 정보와 더불어 다른 감각을 활용할 수 있는 보완된 교수 자료 개발과 같은 적합한 교육 지원이 강 구되어야 할 것이다.

통합교육에 배치된 초등학교와 중·고등학교 인공와우 착용 학 생의 생활 연령, 수술 시기, 착용 기간이 문장 및 이야기 수준의 말지각 수행력에 영향을 미치는지 살펴본 결과에서 생활 연령 과 수술 시기는 유의미한 영향을 주지 않았으나 착용 기간은 중. 고등학생의 SCT를 제외하고 두 집단 모두 착용 기간이 길어질 수록 문장 및 이야기 수준의 점수가 유의하게 낮아지는 것으로 나타났다. 오히려 착용 기간이 길어질수록 낮은 수행력을 보이 는 것은 큰 개인차와 충분한 표집수를 포함하지 않았기에 나타 난 결과일 수 있다. 또한 말지각 점수를 설명하는 설명력의 정도 가 초등학생의 경우 SRT, SCT, CST에서 $36.4 \%, 22.0 \%, 15.7 \%$, 중.고등학생의 경우도 SRT와 CST에서 각각 $4.2 \%$ 와 $16.4 \%$ 로 그 영향력의 미미한 정도를 반영하여 이 세 개의 변인들이 학령 기 이후의 말지각에 미치는 영향은 거의 없음을 알 수 있다. 이 러한 결과는 초등학생 집단의 경우 모든 대상자의 수술 연령이 5세 미만으로 최소한 이 기간 내에 인공와우를 이식받으면 청각 적 뇌가소성(auditory plasticity)과 언어 습득이 활발히 일어나 므로 구어 습득에 적절한 것으로 보고하였으며(Archbold et al., 2008; Manrique et al., 1999), 최소 착용 기간도 36개월 이상으 로 수술 후 2 3년부터 언어능력이 안정적인 발달을 보이기 때 문에(Waltzman et al., 2002) 비교적 동질적인 집단으로 수행력 에 차이가 없는 것으로 설명할 수 있을 것이다. 또 다른 가정은 다수의 연구들(Dunn et al., 2014; Geers, 2004; Geers et al.,
2008)이 인공와우 착용 학생이 학령기나 청소년기 연령에 도달 한 경우 개인차로 인해 수술 시기나 듣기 경험이 더 이상 말지 각 능력에 영향을 미치지 않는다고 하였는데 이처럼 다양한 개 인차가 반영된 결과일 수 있다. Dunn et al.(2014)은 4세 이전에 인공와우 수술을 받은 83명의 아동을 대상으로 7세에서 13세 까지 말지각 능력에 대한 종단 연구 결과에서 7세, 11세, 13세에 서 2세와 4세의 수술 시기 간 말지각 능력에 차이가 없었으며 수술 시기에 따른 다양한 개인차를 보였다고 하였다. Geers (2004)의 연구에서도 8세 이후 학령기 인공와우 착용 학생의 말 지각 수준에 수술 시기가 영향을 주지 않았으며, 고등학생을 대 상으로 한 연구에서도 개인차로 인하여 수술 시기와 착용 기간 이 말지각 수준에 영향을 미치지 않는다고 하였다. 본 연구의 중·고등학교 대상자 23명 중 5세 이후 수술한 학생이 총 6명이 었고 그중 가장 늦게 수술한 학생이 6세 11개월이었다. 이들의 개인별 수행력을 살펴보았을 때, 3명은 만점을 받았고 나머지 3 명은 정상 규준 $-2 \mathrm{SD}$ 보다 저조한 수행력을 나타내므로 큰 개 인차를 나타내었다.

본 연구는 현재 국내 통합학급 환경에 배치되어 있는 인공와 우 착용 학생의 말지각 수준의 다양성을 파악하고자 표집 과정 에서 가능한 모든 대상자를 포함함에 따라 개인차가 크게 나 타나 인공와우 착용에 따른 일반적인 추세나 경향을 도출하지 는 못하였다. 또한 인공와우 착용에 따른 말지각 능력에 미치 는 다양한 요인들이 존재함에도 수술 시기, 착용 기간, 생활 연 령 변인 위주로 살펴보았다는 한계가 있다. 선행연구에서는 인 공와우 착용 학생의 말지각에 영향을 줄 수 있는 다양한 변인 들로 인공와우의 양측 또는 편측 착용 여부(Brown \& Balkany, 2007; Lee \& Sim, 2015), 내이형성부전 및 청신경 결함(Isaiah et al., 2017), 언어 치료 경험 및 언어 수준(Davidson et al., 2011; Park et al., 2016; Quittner et al., 2013), 정보 처리 능력 차이 (Davidson et al., 2011; Pisoni et al., 2011), 우연듣기 기회 부족 과 배경지식의 결여(Park et al., 2016), 청각 기억력과 작업 기억 력 부족(AuBuchon et al., 2015) 등을 보고하였다. 이는 인공와 우 착용 학생의 경우 동일한 수술 시기와 착용 기간에서도 서 로 다른 문장 및 이야기 수준에서 개인차를 보이는 말지각 특 성을 보일 수 있으며, 이들의 말지각 능력이나 특성을 이해하기 위해 생활 연령, 수술 시기와 착용 기간 이외에 다른 변인들을 함께 고려할 필요가 있음을 시사한다.

$\mathrm{KNISE}-\mathrm{DASP}$ 문장 및 이야기 수준 말지각 검사 결과를 종 합해 볼 때, 통합학급에 있는 인공와우 착용 초등학생 및 중고 등학생들은 문장 인지, 문장 이해, 이야기 이해 수준의 말지각 능력에서 큰 개인차를 보였으며, 이러한 개인차는 생활 연령, 수술 시기, 착용 기간의 변인보다는 다른 변인으로 더 설명될 수 있는 것으로 나타났다. 문장 및 이야기 수준의 인공와우의 
말지각 능력을 파악하기 위해 더 심층적이고 체계적인 연구와 더불어 교육 현장에서 개인의 말지각 특성을 고려한 교육 지원 이 모색될 필요가 있을 것이다.

중심 단어 : 통합학급·인공와우·국립특수교육원 말지각발달 검사·문장 검사·이야기 검사.

\section{Ethical Statement}

This study was approved by the Institutional Review Board of Hallym University (HIRB-2014-100).

\section{Acknowledgments}

N/A

\section{Declaration of Conflicting Interests}

There are no conflict of interests.

\section{Funding}

This research was supported by Hallym University Research Fund (HRF-201708-007).

\section{Author Contributions}

All authors contributed equally to this work. S.S. and H.J. designed and performed experiments, analyzed data, and wrote the paper; H.L., K.L., Y.L., and J.P. performed experiments in the clinic; S.S. and H.J. provided statistical analysis and critical revision. Also, the authors discussed the results together and implications and commented on the manuscript at each stage.

\section{ORCID iDs}

Sangyong Shim

https://orcid.org/0000-0003-0501-7963

Hyunsook Jang

\section{REFERENCES}

Archbold, S., Lutman, M. E., \& Marshall, D. H. (1995). Categories of auditory performance. The Annals of Otology, Rhinology, and Laryngology. Supplement, 166, 312-314.

Archbold, S., Harris, M., O’Donoghue, G., Nikolopoulos, T., White, A., \& Richmond, H. L. (2008). Reading abilities after cochlear implantation: The effect of age at implantation on outcomes at 5 and 7 years after implantation. International Journal of Pediatric Otorhinolaryngology, 72(10), 1471-1478.

AuBuchon, A. M., Pisoni, D. B., \& Kronenberger, W. G. (2015). Short-term and working memory impairments in early-implanted, long-term cochlear implant users are independent of audibility and speech production. Ear and Hearing, 36(6), 733-737.

Beadle, E. A., McKinley, D. J., Nikolopoulos, T. P., Brough, J., O’Donoghue, G. M., \& Archbold, S. M. (2005). Long-term functional outcomes and academic-occupational status in implanted children after 10 to 14 years of cochlear implant use. Otology and Neurotology, 26(6), 1152-1160.

Brown, K. D. \& Balkany, T. J. (2007). Benefits of bilateral cochlear implantation: A review. Current Opinion in Otolaryngology and Head and Neck Surgery, 15(5), 315-318.

Convertino, C., Borgna, G., Marschark, M., \& Durkin, A. (2014). Word and world knowledge among deaf learners with and without cochlear implants. Journal of Deaf Studies and Deaf Education, 19(4), 471-483.

Davidson, L. S., Geers, A. E., Blamey, P. J., Tobey, E. A., \& Brenner, C. (2011). Factors contributing to speech perception scores in long-term pediatric cochlear implant users. Ear and Hearing, 32(1 Suppl), 19S-26S.

De Raeve, L. (2010). A longitudinal study on auditory perception and speech

intelligibility in deaf children implanted younger than 18 months in comparison to those implanted at later ages. Otology and Neurotology, 31(8), 1261-1267.

Dunn, C. C., Walker, E. A., Oleson, J., Kenworthy, M., Van Voorst, T., Tomblin, J. B., et al. (2014). Longitudinal speech perception and language performance in pediatric cochlear implant users: The effect of age at implantation. Ear and Hearing, 35(2), 148-160.

Erber, N. P. (1982). Auditory Training. Washington, DC: Alexander Graham Bell Association for the Deaf.

Fagan, M. K. \& Pisoni, D. B. (2010). Hearing experience and receptive vocabulary development in deaf children with cochlear implants. Journal of Deaf Studies and Deaf Education, 15(2), 149-161.

Geers, A. E. (2003). Predictors of reading skill development in children with early cochlear implantation. Ear and Hearing, 24(1 Suppl), 59S$68 \mathrm{~S}$.

Geers, A. E. (2004). Speech, language, and reading skills after early cochlear implantation. Archives of Otolaryngology-Head and Neck Surgery, 130(5), 634-638.

Geers, A., Tobey, E., Moog, J., \& Brenner, C. (2008). Long-term outcomes of cochlear implantation in the preschool years: From elementary grades to high school. The International Journal of Audiology, 47 Suppl 2, S21-S30.

Heo, M. J. \& Kim, L. S. (2010). School performance of children received cochlear implantation under age of five. Journal of Special Education: Theory and Practice, 11(3), 305-337.

Huber, M., Wolfgang, H., \& Klaus, A. (2008). Education and training of young people who grew up with cochlear implants. International Journal of Pediatric Otorhinolaryngology, 72(9), 1393-1403.

Huh, M. J. (2017). A review of inclusive education for hearing impaired students in Korea: Related to cochlear implantation. The Korean Society of Education for Hearing-Language Impairments, 8(1), 71-84.

Isaiah, A., Lee, D., Lenes-Voit, F., Sweeney, M., Kutz, W., Isaacson, B., et al. (2017). Clinical outcomes following cochlear implantation in children with inner ear anomalies. International Journal of Pediatric Otorhinolaryngology, 93, 1-6.

Jeon, E. S. \& Jeong, E. H. (2015). Survey on satisfaction of students with hearing impairment, parents, and teachers to inclusive education. The Korean Society of Education for Hearing-Language Impairments, 6(1), 167-190.

Kim, J. M., Lee, J. H., \& Chun, Y. M. (2014). Effects of age at 2nd implantation on word-in-noise recognition for children with sequential bilateral cochlear implantation. Audiology and Speech Research, 10(2), 138148.

Kim, S. G., Seo, Y. R., \& Ju, M. Y. (2008). A study about speech perception of cochlear implanted children: Toward comparison to speech perception of cochlear implanted children at the age of 6 more or less. Journal of Special Education, 15(2), 163-177.

Korea National Institute for Special Education (2011). A Nation-wide Survey on Special Education. Asan: Korea National Institute for Special Education.

Korea National Institute for Special Education. (2017). A Nation-Wide Survey on Special Education. Asan: Korea National Institute for Special Education.

Ministry of Education. (2018). Special Education Statistics 2018. Asan: National Institute of Special Education.

Lee, Y. M. \& Sim, H. S. (2015). Speech perception benefits of bilateral cochlear implantation for deaf children. Journal of Rehabilitation Research, 19(3), $175-193$

Locke, J. L. (1980). The inference of speech perception in the phonologically disordered child. Part I: A rationale, some criteria, the conventional tests. Journal of Speech and Hearing Disorders, 45(4), 431-444.

Manrique, M., Cervera-Paz, F. J., Huarte, A., \& Molina, M. (2004). Advantages of cochlear implantation in prelingual deaf children before 2 years of age when compared with later implantation. The Laryngoscope, 114(8), 1462-1469.

Manrique, M., Cervera-Paz, F. J., Huarte, A., Perez, N., Molina, M., \& Gar- 
cía-Tapia, R. (1999). Cerebral auditory plasticity and cochlear implants. International Journal of Pediatric Otorhinolaryngology, 49 Suppl 1, S193-S197.

Nicholas, J. G. \& Geers, A. E. (2003). Personal, social, and family adjustment in school-aged children with a cochlear implant. Ear and Hearing, 24(1 Suppl), 69S-81S.

Niparko, J. K., Tobey, E. A., Thal, D. J., Eisenberg, L. S., Wang, N. Y., Quittner, A. L., et al. (2010). Spoken language development in children following cochlear implantation. Journal of the American Medical Association, 303(15), 1498-1506.

Park, H. J., Han, S. A., Choi, J. H., Sim, S. Y., Seo, Y. R., \& Jang, H. S. (2016) The relationship between vocabulary knowledge and speech perception in school-age children using cochlear implants. Communication Sciences and Disorders, 21(3), 488-501.

Park, K. R. \& Shin, E. Y. (2018). Social and emotional characteristics of students with hearing-impaired included in general education classroom. The Korean Society of Education for Hearing-Language Impairments, 9(1), 99-116.

Pisoni, D., Kronenberger, W., Roman, A., \& Geers, A. (2011). Article 7: Measures of digit span and verbal rehearsal speed in deaf children following more than 10 years of cochlear implantation. Ear and Hearing, 32 (1 Suppl), 60S-74S.

Quittner, A. L., Cruz, I., Barker, D. H., Tobey, E., Eisenberg, L. S., \& Niparko, J. K.; Childhood Development after Cochlear Implantation Investigative Team. (2013). Effects of maternal sensitivity and cognitive and linguistic stimulation on cochlear implant users' language development over four years. The Journal of Pediatrics, 162(2), 343-348.e3.

Song, Y. J., Lee, H. J., \& Jang, H. S. (2010). A study on the development of Korean National Institute of Special Education-Developmental Assessment of Speech Perception (KNISE-DASP) for auditory training. Journal of Special Education, 18(1), 3-167.

Svirsky, M. A., Teoh, S. W., \& Neuburger, H. (2004). Development of language and speech perception in congenitally, profoundly deaf children as a function of age at cochlear implantation. Audiology and Neurotology, 9(4), 224-233.

Tye-Murray, N. (2015). Foundations of Aural Rehabilitation: Children, Adults, and Their Family Members. (4th ed.). Stamford, CT: Cengage Learning.

Uziel, A. S., Sillon, M., Vieu, A., Artieres, F., Piron, J. P., Daures, J. P., et al. (2007). Ten-year follow-up of a consecutive series of children with multichannel cochlear implants. Otology and Neurotology, 28(5), 615628.

Venail, F., Vieu, A., Artieres, F., Mondain, M., \& Uziel, A. (2010). Educational and employment achievements in prelingually deaf children who receive cochlear implants. Archives of Otolaryngology-Head and Neck Surgery, 136(4), 366-372.

Waltzman, S. B., Cohen, N. L., Green, J., \& Roland Jr, J. T. (2002). Longterm effects of cochlear implants in children. Otolaryngology-Head and Neck Surgery, 126(5), 505-511. 